\title{
Analysis on the influence of big data era on enterprise financial accounting -- a case study of HUA WEI technologies co., LTD
}

\author{
Wang Yang \\ Dalian university of science and technology, College of Economic and Managementline, dalian, liaoning
}

\begin{abstract}
Big data" is the product of the integration of the highly developed Internet innovation function and various economic fields in today's society. The development of "big data" is bound to bring significant changes in the economic development of today's society. Taking HUA WEI technologies co., LTD., financial aspects based on the development of big data, found big data technology in the application process of the impact of the financial accounting, this era of big data work flow for the company in China, the impact of financial decision-making and financial personnel, and the company response to this phenomenon and make a change, and to analyze its causes and solutions. This electronic document is a "live" template. The various components of your paper [title, text, heads, etc.] are already defined on the style sheet, as illustrated by the portions given in this document.
\end{abstract}

\section{Introduction}

With the advent of the era of big data, great changes have taken place in the collection and analysis of corporate data. The information provided by big data saves a lot of resources to a great extent, which makes human life experience earth-shaking changes and promotes the transformation of corporate financial accounting. As an integral part of the economy, accounting has been deeply influenced by the big data Internet, whether in the transformation of accounting functions, the update of working mode or the construction of informatization. With the development of new information technology bred by "big data" and the emergence of cloud computing and financial sharing center, enterprises of different sizes have found the management mode suitable for the development of their enterprises under the background of the era of big data.

\section{The influence of big data era on huawei}

\subsection{Background analysis of huawei's application in big data}

Huawei is a private enterprise mainly engaged in technology communication, $100 \%$ owned by employees, mainly engaged in the development and operation of radio, microelectronics, communications and other equipment. Huawei is the world's leading manufacturer of information and communications technology solutions. Since its establishment in 1987, huawei has been in the growth stage. In 2010, it entered the global top 500 for the first time, and after that, its ranking continued to soar. In 2018, it entered the world top 100 for the first time, ranking the 83rd among the world's enterprises, and ranking the first in the ranking of Chinese enterprises' net returns.

\subsection{Huawei's financial reform based on big data technology}

\subsubsection{Huawei's financial workflow reform based on big data technology}

\subsubsection{Technological requirements for change}

In the face of the information explosion in the modern society, the traditional financial operation of enterprises is faced with severe challenges. The manual accounting method can no longer meet the needs of the processing of the data generated by the daily business of enterprises, and the human cost keeps rising, leading to a vicious circle of financial problems. Therefore, the reform of financial basic accounting and operation mode is imperative. In the financial report of 2019 , the global sales revenue and year-on-year changes of huawei are shown in table 1. 
TABLE 1 FINANCIAL STATEMENTS OF HUAWEI HOLDING CO., LTD IN 2019

\begin{tabular}{|c|c|c|c|}
\hline $\begin{array}{l}\text { (RMB } \\
\text { million } \\
\text { yuan) }\end{array}$ & 2019 & 2018 & $\begin{array}{c}\text { Compare } \\
\text { d with the } \\
\text { changes }\end{array}$ \\
\hline China & 372162 & 312532 & $19.1 \%$ \\
\hline $\begin{array}{c}\text { Europe, the } \\
\text { Middle } \\
\text { East and } \\
\text { Africa }\end{array}$ & 204536 & 164603 & $24.3 \%$ \\
\hline $\begin{array}{c}\text { The asia- } \\
\text { pacific }\end{array}$ & 81918 & 71199 & $15.1 \%$ \\
\hline $\begin{array}{c}\text { The } \\
\text { americas }\end{array}$ & 47855 & 39470 & $21.3 \%$ \\
\hline other & 14701 & 15817 & $7.1 \%$ \\
\hline A total of & 721202 & 603621 & $19.5 \%$ \\
\hline
\end{tabular}

Huawei accounted for $51.6 \%$ of its sales in mainland China, 28.4\% in Europe, the Middle East and Africa, $11.4 \%$ in Asia Pacific and $6.6 \%$ in the americas. It can be seen that huawei is a global company. In the face of its global business expansion, huawei attaches more and more importance to the European market, and the sales revenue growth rate in 2019 is 5.2\% higher than that in the Chinese mainland market. How to complete the financial work, so that the global financial data can be timely and accurately transmitted to the head office in shenzhen has become a problem. Moreover, in terms of expense reimbursement, such problems as too long time for documents, incomplete original vouchers for reimbursement, non-compliance with the rules for voucher paste and various types of invoices, and noncompliance with the basic financial system, seriously affect the daily accounting of the financial department and the healthy development of the enterprise.

\subsubsection{Innovation in the application of big data technology}

Huawei internal in the face of the urgent problems, caused the company attaches great importance to the high-level, held a meeting set up temporary project group, after three months of internal research, design, development and testing based on the technology of data based on the network under the financial reimbursement system anytime and anywhere - SSE system put into operation inside the company. SSE system is an effective embodiment of the development of big data technology. It assists the daily financial accounting based on the basic functions of data collection, storage and analysis. The flow chart of SSE system operation is shown in figure 1.

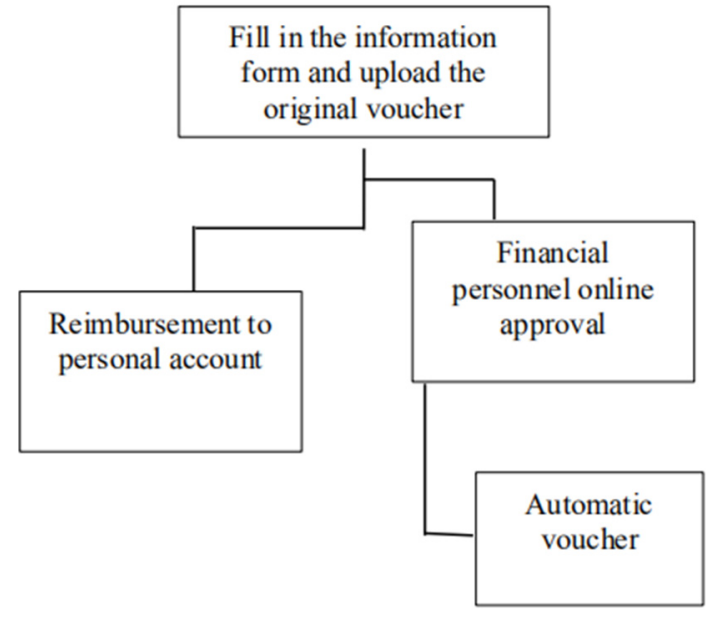

figure $1 \mathrm{SSE}$ system operation flow chart

Before entering the SSE system, fill in the approval electronic flow to initiate the reimbursement process. Self-fill in the expense reimbursement type, which is confirmed by the supervisor, approved by the secondlevel department leader, and sent to the department secretary for review. After the approval, the expense will be remitted to the personal account. In order to save cost, the financial department mainly conducts spot check on reimbursement and records the reputation of employees accordingly, and then determines the probability of spot check according to the reputation of employees. Nowadays, as the system is constantly updated and the reimbursement system of enterprises is constantly improved, based on the trust of employees, "pay first and then review documents" is launched. Now with the continuous development of smart phones, employees can conveniently transfer data by scanning the qr code, and the average accounting processing time is shortened by 2.6 days, which greatly reduces the cost of enterprises.

\subsubsection{Application of big data technology results}

The establishment of enterprise financial reimbursement system changes the chaotic state in the traditional mode, and can solve the problems in a more systematic and creative way. The development of SSE system is a beneficial attempt, which not only improves the work efficiency of the financial department and other relevant departments, but also maintains the security of the enterprise property, guarantees the authenticity of the financial report and achieves good results. And lead more enterprises to carry out the reform and innovation of cost management. Through the experience of this system, the company can effectively manage the cost, which can not only enhance the reliability of the company's financial information, but also improve the working efficiency of the company's financial staff and promote the benign development of the company. 


\subsubsection{Huawei's innovation in financial decision- making based on big data technology}

\subsubsection{Product innovation in decision making}

In the field of financial decision-making, even small and medium-sized enterprises will receive and process and analyze a large amount of financial information and data every day, not to mention a global multinational enterprise like huawei, how to process and store such data before the completion of data center technology has become a problem. Construction in 2012, huawei data center, with 45000 housing supply infrastructure capabilities, and the data center can be regarded as the basis of huawei cloud, unlike many Internet cloud service provider, huawei as equipment provider yourself with hard and soft in combination with total station service ability, there is unique in the data center construction method. With the continuous improvement of data technology, financial sharing service is also proposed, which separates the original financial and human resource management activities scattered in different business units from other activities, and establishes a special independent entity to provide unified services. As an independent functional department, each functional department no longer reports directly to the general manager or legal person of the company, but is managed vertically by each functional department and reports directly to the direct leader of the business.

The financial Commons is like a strong dam. Centralizing similar businesses in one place can save costs and improve services. The function of providing decision-makers with real, accurate and effective timely data that can reflect the development status of enterprises is conceivable.

\subsubsection{The result of product innovation}

Financial sharing center plays an important role in enterprise financial decision-making. After polyhedral efforts, huawei's financial management implements, fully digital, just click the mouse on the other side of the ocean orders can directly enter the supply center in shenzhen, enter the routing process, the continuous improvement of the sharing center, with the fastest speed to support a line of business and decision makers in a timely manner to obtain business data, influence the decision oriented.

\subsubsection{Changes of financial personnel in huawei in the era of big data}

\subsubsection{In the era of big data, huawei has new requirements for financial personnel}

Ren zhengfei, then huawei's CFO (chief financial officer), found loopholes in the financial management led by huawei's financial staff, let IBM enter huawei and required it to improve the financial management of huawei.IBM has trained thousands of qualified financial department managers who are able to participate in decision-making for huawei. They go deep into the sales, marketing, $r \& d$ and other departments of huawei to improve the level of the overall financial staff and bring standardized financial processes to all departments of huawei, thus achieving the balanced development of revenue and profit. In March 2018, meng wanzhou took over as CFO of huawei and proposed four new requirements to huawei's financial staff:

- "Huawei's financial management in warp and weft has become a world class, so it is necessary to strengthen the optimization of weft management. At the same time, try to tamp down the base so that good management continues to sink down, go to the scene to solve problems, and empower in combat."

- "Business people need to understand finance, and financial people need to understand business, to form a strong concrete system."

- "Strengthen the capacity building of financial dimension, take the lead in producing a group of financial scene division."

- "The financial and economic secretariat has fully listened to the criticism and demands for internal management from all sides and worked hard to build the capacity base and serve the business well."

\subsubsection{The result of personnel change}

Today, huawei's financial team is made up of hundreds of outstanding graduates from Cambridge, harvard, Oxford and other world famous universities. At its peak, the "paying craftsmen" who need to write 3,000 chapters a day have worked for decades in a high-power and high-pressure environment, handling hundreds of billions of dollars without any mistakes. With the improvement of the quality of huawei's financial staff, it can provide more accurate financial data for various operating organizations and continue to provide customers with high-quality comprehensive solutions.

Under the image of financial and technological change, huawei keeps playing. By the end of 2019, huawei's total assets had grown from $\$ 5,670$ in 1978 to $\$ 65.3$ billion, and its workforce had grown to 188,000 . It operates in more than 170 countries and regions, serving more than one-third of the world's population. Huawei has always been committed to the concept of "bringing the digital world into every person, every family and every organization", constantly innovating and creating. At the 2018 New Year conference, meng wanzhou, huawei's chief financial officer, mentioned that "the responsibility not written in management is our elective course", saying that the current finance not only meets the daily financial accounting treatment, but also takes the responsibility. Therefore, the idea of big data technology has been integrated into the financial accounting work of huawei. Huawei insists on spending more than $10 \%$ of its annual sales on research and development. From 2008 to 2018, huawei spent 488 billion yuan on r\&d in the past decade. On March 29, huawei officially released its financial statements for 2019 , with total sales revenue of 72.12 billion yuan, up 
$19.5 \%$ year on year.Net profit was 59.3 billion yuan, up $25.1 \%$ year on year. The r\&d expenditure in 2019 was 105.1 billion yuan, accounting for $14.1 \%$ of the annual revenue, up $13.2 \%$ year-on-year. Huawei's high investment in science and technology research and development is the basis for its continuous expansion, development and profitability, and provides an effective guarantee for the development of big data technology and other digital technologies in China.

\section{Analysis of the impact of big data on enterprise financial accounting}

\subsection{Impact on financial workflow}

\subsubsection{Changes to financial workflow normalization}

The traditional financial work steps are complicated and the process is tedious, but financial accounting is the top priority of the financial department and even the entire enterprise, which requires the use of manual methods to record vouchers, cost accounting to calculate costs, calculate financial data, and formulate financial statements. Repetitive work, encountered calculation errors also need to audit the accounts, and gradually correct, the workload can be imagined.

The application of modern technology of big data can free accountants from the tedious calculation work, give them more time to dig the value of data information, make the accounting work get effective specification, and gradually complete the transformation. Financial workflow based on big data technology, as shown in figure 2 .

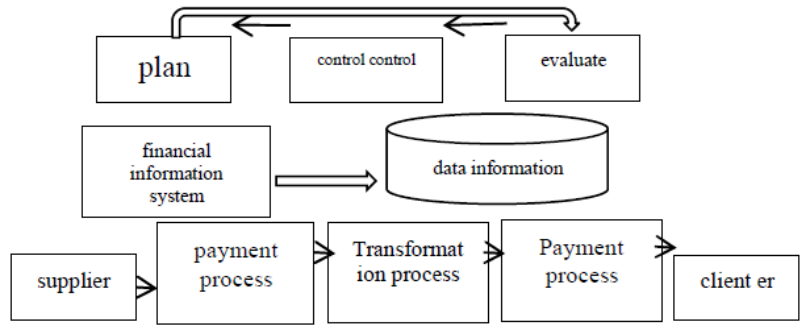

figure 2 Financial flow chart based on big data

The collection, analysis and processing of accounting information are more efficient, and the timeliness and integrity of data information are well guaranteed. In addition, the standardization of the work of the financial department will make the communication between the financial department and other departments more convenient, break down the barriers between departments, improve the scientific transmission effect, and promote the scientific and effective use of all resources of the enterprise.

\subsubsection{Real-time change of financial working time and space}

\subsubsection{Financial work overcomes time and space constraints}

With the continuous expansion of the company's scale and the establishment of subsidiaries and subsidiaries, in the traditional mode, the head office is unable to obtain the financial information of subsidiaries or subsidiaries in a timely and effective manner, and the data lag gradually shows its drawbacks. Financial information USES Internet technology to create information network, strengthen the transfer and communication of financial information in different regions or countries, save the time of financial information conversion, and greatly improve the working efficiency of financial information. At the same time, it is difficult to modify financial information or data through the Internet technology of big data to effectively prevent disclosure and ensure the security of financial information. So that enterprise managers or other units can accurately understand the financial status and operating status of the enterprise, the financial information more accurate, more conducive to the decision-making of managers.

\subsubsection{Financial work became paperless}

Most of the business accounting work in the big data environment has been informationized and networked. Much of what used to be the manual work of financial accounting has been converted to the current electronic work on the Internet, and the old paper version has been converted to the current electronic version. At the same time, as long as there is a network at home or on a business trip, financial information can be consulted. The signature of the supervisor can also be carried out on the network. With the development of big data technology, financial work has become more convenient and fast. Under big data technology, all information is stored, processed and analyzed to increase its utilization and reduce the corresponding cost.

\subsection{Impact on financial decisions}

\subsubsection{Changes in the accuracy of financial decisions}

With the advent of the era of big data, the data sources of enterprises are also increasing, and the data obtained by enterprises are also increasing. The data results obtained from analysis are more accurate than before, which can support the financial decisions of the next quarter more persuasively, so that enterprises can reduce losses and increase revenue. Through the analysis of accounting information, accountants can understand the financial status and operation of the enterprise, identify various risks that the enterprise may encounter in the future investment process, so as to choose the appropriate investment projects, promote the improvement of enterprise benefits, and significantly enhance the market competitiveness of the enterprise. 


\subsubsection{Simplified changes to the financial decision-making framework}

\subsubsection{The change from traditional enterprise financial decision making to enterprise decision making in the era of big data}

The decision-making process of traditional enterprises is mainly divided into four steps, and the specific contents are shown in figure 3.

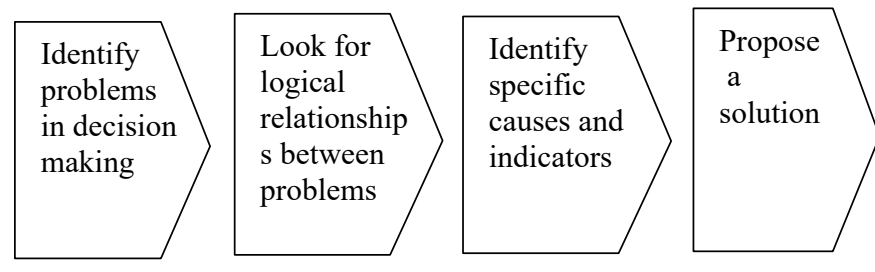

figure 3 Traditional enterprise decision flow chart

From the analysis of the figure, it can be concluded that previous financial decisions attach great importance to the causal logic between decision problems. Through the analysis of the causal relationship, the key factors leading to the problems are found out, and the solutions relative to the problems are finally formulated. This is only relative to the front-end data base of the financial information of structured data analysis and decision, is not able to fully reflect the reality of the enterprise and the market situation, the era of big data is brought about by the financial personnel facing the generation of unstructured data, for these from the various channels to obtain the relative to the backend of non-financial data of unstructured data analysis combined with structured data analysis so as to make an accurate financial decisions, this is now the financial personnel should do.

The financial process based on big data technology is also divided into four steps, as shown in figure 4.

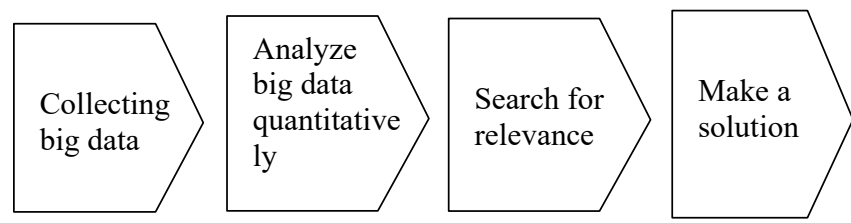

figure 4 Financial flow chart based on big data

\subsubsection{The implications of changing the decision framework}

Big data formed in the environment of a large amount of data resources to make the enterprise can move through the financial big data platform for social networks and other modern media, collect related to financial industry a great deal of data and rich resources, and then the quantitative data and the corresponding data analysis, and use the large data computing technology to the realtime accurate data processing, and then through the analysis of data mining out hidden behind the financial data of all kinds of data correlation. In the process of analysis, each isolated and seemingly unrelated data is analyzed to integrate internal correlations and dig out relevant contents. Based on the change in this way, the financial staff should look at the overall situation and comprehensively consider various data indicators, so as to achieve the reasonable allocation of resources and ensure the efficient operation of the enterprise.

\subsection{Impact on financial work participants}

\subsubsection{Urgently need compound finance and accounting talents}

It can be seen from the analysis of the present majority of financial accounting industry participants that the overall comprehensive quality of financial accounting personnel is not high enough, which greatly affects the quality of financial work and the development process of enterprises. The main performance is as follows:

- after the cancellation of accounting professional qualification certificate, the threshold of accounting professional is constantly lowered, accounting work does not need qualification certificate. As a result, most accountants' understanding of the industry is too limited to meet the needs of sustainable development.

- the proportion of senior financial management personnel in the financial industry is relatively low. At the same time, the existing management personnel have low management ability. Most of them are selected from grassroots financial personnel, and they have a serious lack of knowledge in auditing and financial management.

- the current status of accounting personnel most of them are satisfied with the status quo, do not care about the annual changes in the accounting laws and regulations of the update, resulting in their accounting knowledge system obsolete, do not comply with the work of national laws and regulations, affect the development of enterprises.

\subsubsection{The thinking mode of management is backward}

In fact, in the era of big data, on the other hand, is to analyze the result of the financial and accounting data capacity is too large, and affected by various factors data management system of chaos, and make mistakes in data management and dislocation of the financial and accounting data is stored in the finance and accounting data analysis, it is wrong to start data, decision-making report is not accurate, the loss of the enterprises will continue to increase; On the other hand, the amount of financial accounting data is huge and complex, while the scale of data storage is relatively limited, there may be some confusion in data management, but the worst is the impact of financial personnel's knowledge level, the degree of data system chaos will be worse.

\section{4 peroration}

In the era of rapid development of science and technology of big data, enterprise data of the diversity 
and richness, not just for financial accounting works offers a variety of channels, and for financial accounting in the decision-making of the financial policy to extract valuable information is also a deeper provides a rare opportunity, make the enterprise and enterprise, between enterprise and society can share information, and constantly promote social and economic development. Enterprise, therefore, it is necessary to seize the development opportunity of the era of large data, financial accounting should also learn to face all kinds of change under the condition of reasonable operation, do the people-oriented, pay attention to the development of accounting personnel, establish and perfect to adapt to the era of big data in the accounting information system, and take effective measures to actively cope with difficulties and challenges brought by the era of big data, make enterprise to seek steady .

\section{References}

1. Chen min. Research on the transformation of financial accounting to management accounting under the background of big data $[\mathrm{J}]$, modern marketing (next issue), Mar 2019.

2. fu miao. Discussion on financial strategic management of enterprises in the era of big data $[\mathrm{J}]$, tax payment, 2019.

3. li wenhua. Strategic analysis of financial accounting development under the condition of Internet $+[\mathrm{J}]$, China management informatization, 2019.

4. wu yanhong, lun shuqing. Analysis on the impact of Internet big data era on financial accounting [J], modern business and trade industry, 2019.

5. liu xuechao. Discussion on enterprise financial transformation in the era of big data $[\mathrm{J}]$, finance and accounting study, 2018. 